Correspondence: B Cartmill, Ophthalmology

Department, Eye and Ear Building, Royal Victoria

Hospital, Grosvenor Road, Belfast BT12 6BA,

Northern Ireland Tel: + 353289063 3693,

Fax: + 3532890634684 .

E-mail: barrycartmill@hotmail.com

Neither author has any proprietary interest arising from this publication. This work has not been previously presented at any major meeting and has not been submitted to any other journal

Eye (2006) 20, 1388-1390. doi:10.1038/sj.eye.6702228; published online 20 January 2006

Sir,

\section{Outcomes of macular hole surgery}

We note with interest that Jaycock et al, ${ }^{1}$ in their report on the outcomes of macular hole surgery, found no evidence of ICG retinotoxicity. This is based on their findings that patients who underwent indocyanine green (ICG) assisted internal limiting membrane (ILM) peel had better anatomical and visual outcomes than both the ILM peel group as a whole or those who had no ILM peel. As they noted there are many publications on the subject of ICG toxicity to the retina, often with contradictory conclusions. We have previously reported our experience with ICG-assisted ILM peel. ${ }^{2}$ Our patients achieved a high rate of anatomical hole closure but visual results were disappointing. As a result of these findings we performed an audit of macular hole surgery in our department. This confirmed the poor visual outcome with ICG-assisted ILM peel described in our paper and recommended we discontinue ICG use and use Trypan blue as an alternative. Our current practice is to use membrane blue (DORC International bv, Zuidland, Holland) for all cases requiring ILM peel. Recently, we have reaudited our macular hole outcomes in light of this change in practice.

The anatomical success and visual improvements of both our initial and repeat audit are summarised in Table 1. The high rate of anatomical hole closure with ICG remains with membrane blue but without the adverse effect on visual outcome we experienced with ICG. No other aspects of surgery have changed between the two audits with the vast majority of the surgery performed by the same two vitreoretinal surgeons. We believe our audit results confirm the potentially toxic effect of ICG on the retina. As discussed in our initial paper the concentration of ICG may be the main factor
Table 1 Anatomical and functional outcomes following macular hole surgery

\begin{tabular}{lcccccc}
\hline & \multicolumn{2}{c}{ Initial audit } & & \multicolumn{2}{c}{ Reaudit } \\
\cline { 2 - 3 } \cline { 5 - 6 } & $\begin{array}{c}\text { All } \\
\text { cases } \\
(\mathrm{n}=123)\end{array}$ & $\begin{array}{c}\text { ICG cases } \\
\text { only } \\
(\mathrm{n}=21)\end{array}$ & & $\begin{array}{c}\text { All } \\
\text { cases } \\
(\mathrm{n}=27)\end{array}$ & $\begin{array}{c}\text { Membrane } \\
\text { blue cases } \\
\text { only } \\
(\mathrm{n}=17)\end{array}$ \\
\hline $\begin{array}{l}\text { Anatomical success (\%) } \\
\begin{array}{l}\text { Visual improvement } \\
\text { (Snellen-converted }\end{array}\end{array}$ & 0.48 & 92 & & 81 & 100 \\
logMAR) & & 0.03 & & 0.4 & 0.41 \\
\hline
\end{tabular}

influencing functional outcome. This appears to be supported by the recent paper by Jaycock $e t$ al, as they found no evidence of toxicity with a $0.05 \%$ solution of ICG while our adverse outcomes followed use of a $0.5 \%$ solution. In light of our audit finding we will continue to use membrane blue to assist in ILM peeling but ICG does appear to be safe in low concentrations.

\section{References}

1 Jaycock PD, Bunce C, Xing W, Thomas D, Poon W, Gazzard G et al. Outcomes of macular hole surgery: implications for surgical management and clinical governance. Eye 2005; 19: 879-884.

2 Posselt D, Rahman R, Smith M, Simcock PR. Visual outcomes following ICG assisted ILM peel for macular hole. Eye 2005; 19: $279-283$.

M Smith, P Simcock and R Ling

West of England Eye Unit, Royal Devon and Exeter Hospital, Barrack Road, Exeter EX2 5DW, UK

Correspondence: M Smith,

Tel: + 411392406008 ;

Fax: + 411392406022

E-mail: smith@mic73.freeserve.co.uk

Eye (2006) 20, 1390. doi:10.1038/sj.eye.6702231; published online 20 January 2006

Sir, Report of a novel lobular chorioretinal dystrophy

Atrophy involving the choroid and retina is a consequence of infective, inflammatory, or degenerative 